\title{
Influence of nonlinearities on the efficiency and accuracy of FEM calculations on the example of a steel build-up thin-walled column
}

\author{
Patryk Deniziak ${ }^{1, *}$ and Karol Winkelmann ${ }^{1}$ \\ 1 Gdańsk University of Technology, Faculty of Civil and Environmental Engineering, \\ Narutowicza 11/12, 80-233 Gdańsk, Poland
}

\begin{abstract}
Due to the increase of computing capabilities of standard processing units, it is possible to perform complex analyses, considering a number of nonlinearities, such as geometric, material and boundary (contact) even on personal computers. In the paper, the authors have analysed the efficiency and accuracy of standard PC's FEM calculations performed in Abaqus CAE 2017 software on the example of a critical load assessment of a thin-walled steel column element with selected nonlinearities. A cross-section shape of a built-up column used by an international steel structures manufacturer was adopted. The analysis serves to check the behavior of their product. Several types of FEM analysis, strictly based on the EN standard regulations were performed. In turn, the relation of computational time to the adopted analysis type was obtained. Moreover, the produced load values in different types of independent calculation were compared and analysed. A possible future development in the field, based mainly on full-scale experimental tests, was also highlighted.
\end{abstract}

\section{Introduction}

The computation power of a standard processing unit (a single computer station) is still increasing and has now reached a level that allows solving quite complicated computational tasks even on a personal computer. This introduced a broader adaptation and popularization of numerical modelling in civil engineering. Modern commercial CAE software uses mainly the Finite Element Method (FEM) to solve the structural mechanics problem and efficient graphical post-processing environments to visualize to stress-strain dependencies. The FE methods are strongly affected by computer processing parameters, FE model detailing and undertaken analysis mode, the last factor being the subject of the paper.

The authors have analysed the efficiency and accuracy of FEM calculations performed in Abaqus CAE software (v. 2017) on an example of a structural response of a thin-walled steel column element with an addition of selected nonlinearities. The analysis is step-wise, observing said parameters after each load increment. The Abaqus CAE software allows to consider material, geometric and boundary condition (contact) nonlinearities, which are

\footnotetext{
*Corresponding author: patdeniz@pg.edu.pl
} 
proven to have significant impact on the model behaviour - their appropriate adoption in the model helps obtaining an exact image of a real structural response.

Authors would like to thank the Academic Computer Centre in Gdansk CI TASK (Polish: Centrum Informatyczne Trójmiejskiej Akademickiej Sieci Komputerowej) for sharing the Abaqus CAE software licence.

\section{Element description}

Since a cold-formed technology has become popular in steel constructions, many companies patented proprietary element shapes. Experimental laboratory tests of some cold-formed elements are presented in [1-5]. The authors have chosen a cross-section shape of a built-up thin-walled column designed and implemented by an international steel structures manufacturer. The analysis serves to check the behaviour of the product. Other manufacturer solutions were also tested and are presented in [6].

The analysed column consists of two chords - the thinnest elements has been chosen out of the company product catalogue. Cross-section wall thickness is equal to $t=3 \mathrm{~mm}$.

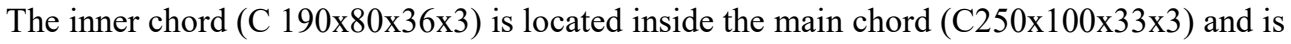
stiffening the whole element. C-sections are mutually connected by rows of M12 bolts (class of 8.8). The cross-section of the column is shown in Figure 1.

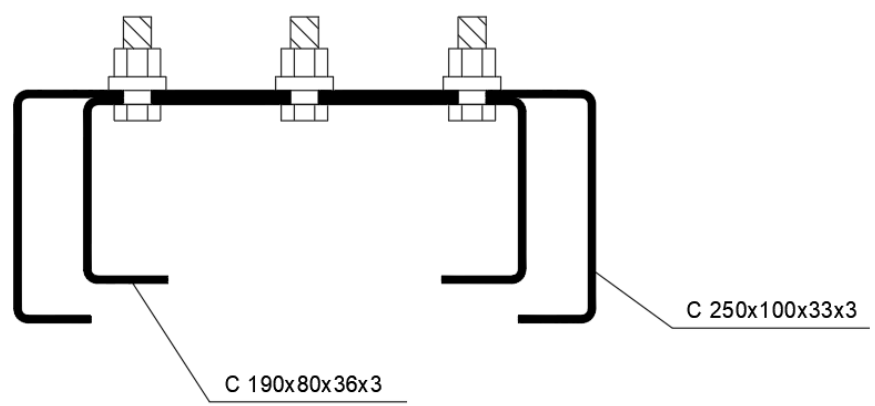

Fig. 1. The analysed built-up column cross-section.

Total lengths of the main elements are equal to $3350 \mathrm{~mm}$ (the outer one) and $2700 \mathrm{~mm}$ (the inner one). A length difference indicates that the outer chord is not stiffened along entire length. The overview of the column, presenting the spacing between rows of bolts on both elements, is given in Figure 2. A bolt rows arrangement influence on the column resistance was analysed and is presented in [7].

The element is made of $\mathrm{S} 350 \mathrm{GD}+\mathrm{Z}$ steel. It should be noted, that the connection between the column and the bottom plate is designed in the same way they are assembled in the real-life structures of this kind.

\section{FEM calculations}

\subsection{Model description}

The authors have decided to check how the computational model complexity influences the efficiency and accuracy of the FEM calculation process. Nonlinearities are complement every forthcoming step of the numerical calculations, which makes the model more similar to the real-life construction, yet more complex at the same time. 
The column has been represented with square S4R shell elements located on a grid of nodes, their total number is equal to 59.900. As bolts are much stiffer than thick plates, connectors have been modelled as super-stiffened wire elements connected to two circular shells. These circular shells were tied to both inner and outer chord. Stresses and deformations in bolts are not taken into account in this analysis.

A gap between closely-spaced shell planes is modelled as a distance between middle surfaces of shells. In case of chords, the gap is equal to $3 \mathrm{~mm}$, representing the true distance between middle surfaces of steel elements. In fact, chords are closely-spaced and touch each other all along. This normal and frictional interaction was modelled by a proper contact law.

A bottom horizontal plate surface is fully fixed and the main chord top edge has its horizontal displacements blocked. The rest of degrees of freedom in the column head are free (including all rotations). The element is axially compressed by a nodal force subjected in the centroid of the main chord.

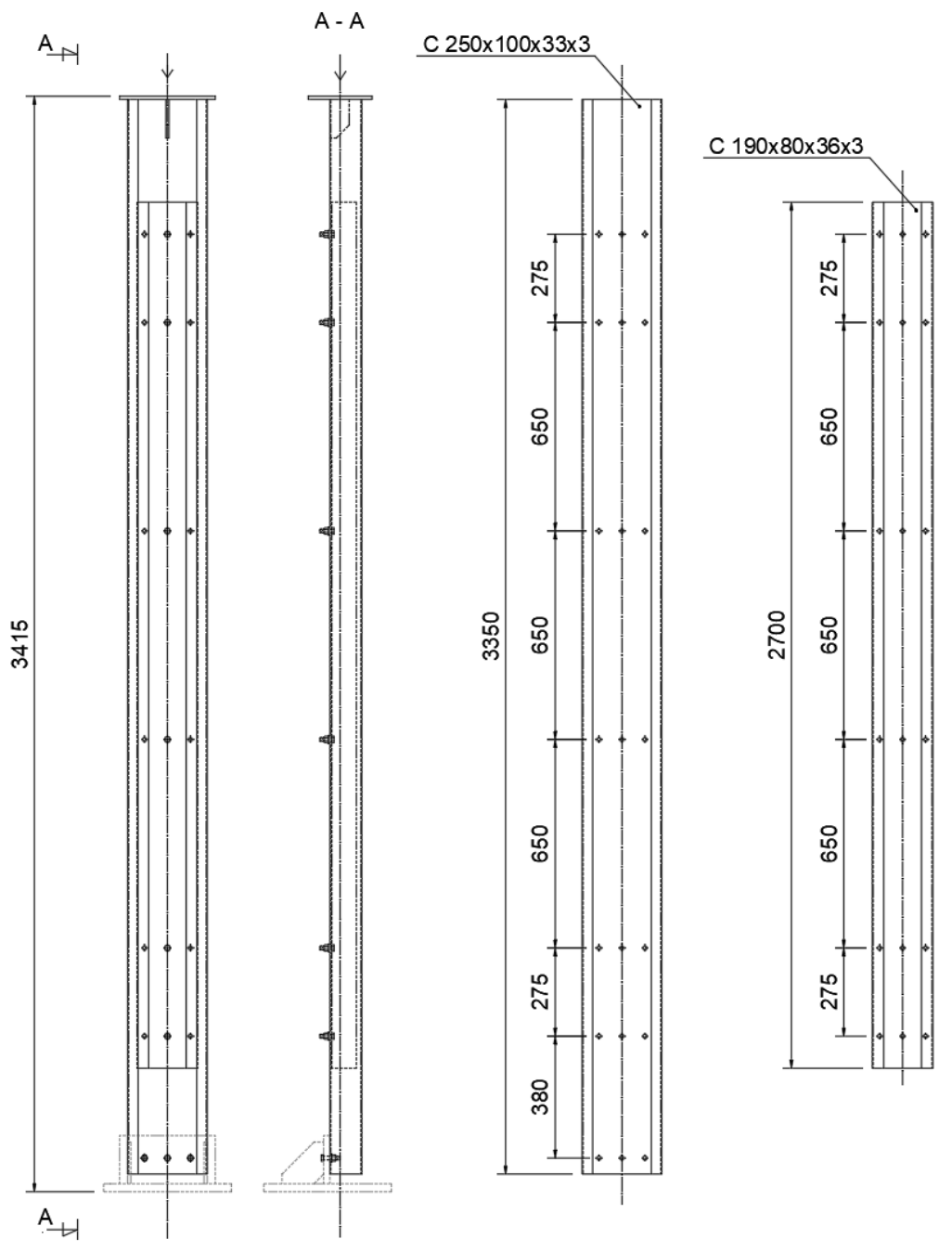

Fig. 2. The analysed built-up column overview, with both chords' dimensions given. 


\subsection{Types of analysis}

Several types of FEM analysis are strictly based on the EN standard regulations. These standards recommend considering imperfections and nonlinearities in the computational model to make it more complex and exact. As previously mentioned, three different kinds of nonlinearities are taken into account: the material, geometric and boundary condition (contact) nonlinearities. The abbreviations used by the authors in the following chapters are taken accordingly to EN 1993-1-6 [8] guidelines. This set is then further expanded by the Authors' analysis considering a set of contact nonlinearities. The list of used types of analysis with their abbreviations are presented in Table 1.

Table 1. Considered types of linear and nonlinear analyses and their abbreviations according to EN 1993-1-6 [8].

\begin{tabular}{|l|l|}
\hline \multicolumn{1}{|c|}{ Analysis type } & \multicolumn{1}{c|}{ Abbr. } \\
\hline Linear elastic Analysis & LA \\
\hline Linear elastic Bifurcation (buckling) Analysis & LBA \\
\hline Geometrically Nonlinear elastic Analysis & GNA \\
\hline Materially Nonlinear Analysis & MNA \\
\hline Contact Nonlinear Analysis & CNA \\
\hline Geometrically and Materially Nonlinear Analysis & GMNA \\
\hline Geometrically and Materially Nonlinear Analysis including Contact & CGMNA \\
\hline
\end{tabular}

The full linear analysis (LA) is the simplest one and should be performed at the beginning. This analysis is fast and does not require much computer resources but is relevant only when the load is relatively small (stresses do not exceed yield strength). This analysis gives an opportunity to check the correctness of all model assumptions and assembly.

Linear bifurcation analysis (LBA) has been carried out as well to determine eigenvalue buckling load. The biggest advantage of this analysis is its fast stability load value convergence, however it is still full linear. The issues of true material and structural behaviour have not been considered yet.

Nonlinear analyses are characterized by the fact that load is divided into increments and the stiffness matrix has to be aggregated again every time after inputting these increments. Furthermore, stiffness is changing with the load increments. This is a feature shown by all real-life engineering structures. Also, the stability path is no longer linear. Nonlinear analysis represents a more realistic response of the considered structure than its linear equivalent.

Table 2 presents availability of the FE most common model used nonlinearities with regard to the type of analysis.

Table 2. The availability of nonlinearities in dependence on the type of particular analyses in FEM.

\begin{tabular}{|c|c|c|c|c|}
\hline Abbr. & $\begin{array}{c}\text { Full linear } \\
\text { analisis }\end{array}$ & $\begin{array}{c}\text { Large } \\
\text { deformation } \\
\text { theory }\end{array}$ & $\begin{array}{c}\text { Nonlinear } \\
\text { elasto-plastic } \\
\text { material law }\end{array}$ & $\begin{array}{c}\text { Boundry } \\
\text { conditions } \\
\text { nonlinearity }\end{array}$ \\
\hline LA & YES & NO & NO & NO \\
\hline LBA & YES & NO & NO & NO \\
\hline GNA & NO & YES & NO & NO \\
\hline MNA & NO & NO & YES & NO \\
\hline CNA & NO & NO & NO & YES \\
\hline GMNA & NO & YES & YES & NO \\
\hline CGMNA & NO & YES & YES & YES \\
\hline
\end{tabular}




\subsubsection{Material nonlinearity}

Materially nonlinear analysis employs (among others) an elasto-plastic material law. Steel stress-strain relation is linear only when yield stresses are not reached. Reaching after this point, the curve becomes more unstable and unpredictable. Elasto-plastic material model allows to consider permanent plastic deformation influence on global stability of the element.

Figure 3 represents the stress-strain curve taken into account in the mentioned materially nonlinear analysis. Yield stress is equal $350 \mathrm{MPa}$ and an ultimate strength is assumed as $420 \mathrm{MPa}$ according to [8]. The stress-strain curve is a simplification of a S350 $\mathrm{GD}+\mathrm{Z}$ steel curve found in [9].

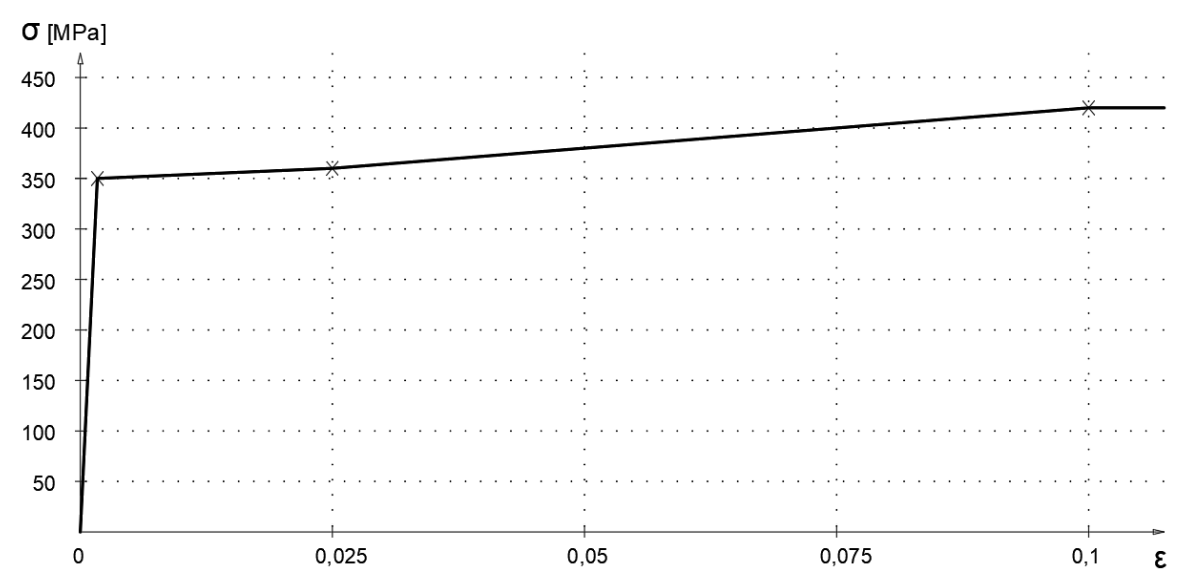

Fig. 3. Stress-strain curve taken into account in the undertaken materially nonlinear analyses.

\subsubsection{Geometric nonlinearity}

Geometrically nonlinear analysis incorporates a large deformation theory. The element shape is subjected to large-scale deformations, which is considered during the analysis in the form of a relevant variation in the element stiffness. The position of the load is also changing, following the element deformation. The change in the shape of the structure is sometimes very rapid. For example, some convex shells may snap through during the loading processes, changing the stiffness significantly. This phenomenon is presented graphically in [10].

\subsubsection{Boundary condition nonlinearity}

Boundary condition nonlinearity includes the contact between model parts what is shown in [11]. Without the contact added, both chords are able to penetrate through each other, an effect which is not possible in real-life structure. The contact enables the occurrence of frictional forces, which allows for a shared response of both chords - since the parts of the model work accordingly, the stiffness rises rapidly. Also, for this analysis scenario, the structural deformation is no longer linear. 


\subsection{Mixed analyses}

Combined mixed analyses have also been carried out. Geometrically and materially analysis (GMNA) and geometrically and materially analysis with contact (CGMNA) steps were created. Since the most accurate mapping of the structural response is obtained in these modes of the analysis, the solution of these methods may act as an reference solution.

\section{Results and conclusions}

All computational steps were solved on a traditional PC, equipped with i7-6700 CPU unit, with a processor working at $3.40 \mathrm{GHz}$. All 4 cores and 8 threads of the processing unit were involved. Before reliable results were received, the CPU unit was being warmed-up. Individual details of each type of the analysis are presented in Table 3.

Table 3. Analysis load, time and maximal deformation obtained for each considered analysis type.

\begin{tabular}{|c|c|c|c|c|}
\hline & Load & Time & $\begin{array}{c}\text { Max } \\
\text { deformation }\end{array}$ & $\begin{array}{l}\text { Max vertical } \\
\text { deformation }\end{array}$ \\
\hline LA & $\begin{array}{l}160 \mathrm{kN} \\
400 \mathrm{kN}\end{array}$ & $\begin{array}{l}50 \mathrm{~s} . \\
51 \mathrm{~s} .\end{array}$ & $\begin{array}{c}5 \mathrm{~mm} \\
12 \mathrm{~mm} \\
\end{array}$ & $\begin{array}{l}2 \mathrm{~mm} \\
4 \mathrm{~mm}\end{array}$ \\
\hline LBA & $\begin{array}{c}161 \mathrm{kN} \\
\text { (minimum value) }\end{array}$ & $1 \mathrm{~min} 51 \mathrm{~s}$ & $1 \mathrm{~mm}$ & - \\
\hline GNA & $\begin{array}{c}160 \mathrm{kN} \\
250 \mathrm{kN} \\
319 \mathrm{kN}^{*}\end{array}$ & $\begin{array}{l}1 \min 23 \mathrm{~s} . \\
1 \min 21 \mathrm{~s} . \\
2 \min 25 \mathrm{~s} .\end{array}$ & $\begin{array}{c}7 \mathrm{~mm} \\
19 \mathrm{~mm} \\
48 \mathrm{~mm} \\
\end{array}$ & $\begin{array}{l}2 \mathrm{~mm} \\
4 \mathrm{~mm} \\
9 \mathrm{~mm}\end{array}$ \\
\hline MNA & $\begin{array}{l}160 \mathrm{kN} \\
250 \mathrm{kN} \\
319 \mathrm{kN} \\
350 \mathrm{kN} \\
400 \mathrm{kN} \\
\end{array}$ & $\begin{array}{l}1 \mathrm{~min} 20 \mathrm{~s} . \\
1 \min 19 \mathrm{~s} . \\
2 \min 30 \mathrm{~s} . \\
2 \min 01 \mathrm{~s} . \\
3 \min 45 \mathrm{~s} .\end{array}$ & $\begin{array}{c}5 \mathrm{~mm} \\
7 \mathrm{~mm} \\
24 \mathrm{~mm} \\
65 \mathrm{~mm} \\
337 \mathrm{~mm} \\
\end{array}$ & $\begin{array}{c}2 \mathrm{~mm} \\
4 \mathrm{~mm} \\
17 \mathrm{~mm} \\
46 \mathrm{~mm} \\
237 \mathrm{~mm} \\
\end{array}$ \\
\hline CNA & $\begin{array}{l}160 \mathrm{kN} \\
250 \mathrm{kN} \\
319 \mathrm{kN} \\
350 \mathrm{kN} \\
400 \mathrm{kN} \\
\end{array}$ & $\begin{array}{l}4 \min 29 \mathrm{~s} . \\
4 \min 46 \mathrm{~s} . \\
5 \min 11 \mathrm{~s} . \\
5 \min 27 \mathrm{~s} . \\
5 \min 12 \mathrm{~s} .\end{array}$ & $\begin{array}{c}5 \mathrm{~mm} \\
8 \mathrm{~mm} \\
10 \mathrm{~mm} \\
11 \mathrm{~mm} \\
13 \mathrm{~mm} \\
\end{array}$ & $\begin{array}{l}2 \mathrm{~mm} \\
3 \mathrm{~mm} \\
3 \mathrm{~mm} \\
4 \mathrm{~mm} \\
4 \mathrm{~mm} \\
\end{array}$ \\
\hline GMNA & $160 \mathrm{kN}^{*}$ & $1 \min 33 \mathrm{~s}$. & $7 \mathrm{~mm}$ & $1 \mathrm{~mm}$ \\
\hline CGMNA & $162 \mathrm{kN} *$ & $9 \min 19 \mathrm{~s}$. & $8 \mathrm{~mm}$ & $2 \mathrm{~mm}$ \\
\hline
\end{tabular}

* the cases where further loading was not possible due to model's global instability

In all cases of static general analysis in Abaqus, the load applied to the element was gradually increased up to $400 \mathrm{kN}$. This is a value equal to the maximum load value of a planned experimental compressive tests due to the limitations of both the test stand and the equipment. Although, it should be pointed out, that reaching a load value of $400 \mathrm{kN}$ was not possible in some analysed scenarios due to the global instability of the model. The first load increment was set as $10 \%$ of the maximum load. Further increment values were automatically selected by the software.

Geometrical analysis, either free of nonlinearities or combined with nonlinearities, identifies a significant role of second-order effects on the total load-carrying capacity of the column. The bottom connection eccentricities initiates an unintended bending moment that is not neglected in successive load increments. Taking the above mentioned 
phenomenon into account, a second-order effect - based decrement of the maximum load that the element can carry should be considered. Considering the most complex analysis (GMNA and CGMNA) indicates the total load-carrying capacity of the column equals approximately to $160 \mathrm{kN}$. Therefore, the level of $160 \mathrm{kN}$ has been set as reference load level for each step.

The first critical load value, obtained for the analysed column is equal to $161 \mathrm{kN}$. What is worth mentioning, a local deformation of the main chord in its bottom area is observable instead of a global stability loss - it indicates the importance of the second-order effects in the supports both in the model and in planned experimental tests.

The total calculation time increases together with model complexity, as expected. Amongst many factors, the contact consideration was proved to put the strongest impact on the extension of the calculation time - the computational process was exceeding the linear elastic analysis computational time by over $500 \%$. Furthermore, the CGMNA scenario increases the total calculation time by more than 10 times.

In this specific case, the GMNA analysis turned out to be the most favourable one from the time-consuming point of view.

Disregarding the calculation time, the correctness of all mentioned model assumptions should be verified, for example by planned natural scale experimental compressive tests.

\section{Future development of the topic}

In the presented calculations the load values are obtained solely on the basis of numerical calculations. However, the FEM calculations should only act as a representation of the real-life structural response. The values of numerical calculations should not be relating to each other, but they should be referred to an experimentally obtained value. This said, a full scale experimental test of the column is being prepared, and the results of computations will be then compared to the obtained results.

Also, the calculations should be performed parallelly on two or more computers of similar parameters, this way two interesting conclusions may be specified - the relation of computational time to the computing power of the $\mathrm{PC}$ and the mean value of the load-time relation produced on the basis of independent calculation. Moreover, for the power-time relation, such multiple tests on different processing units may indicate if this relation is linear or not.

In the next step, it is also worth checking the calculation scenario of constant load increment for every analysis type blocking the possibility of automatic load increment selecting because small differences may depend on this factor.

An addition of geometrical imperfections in the form of first eigenmode of the column elements to the model is also planned, in order to make the model even more similar to real-life structures of this kind in terms of its response. Implementing this imperfection should verify the obtained load-carrying capacity of the column model and should result in interesting observations. Example of geometric imperfection measurements on cold-formed steel channels is presented in [12].

Due to the fact, that the column is designed and implemented by an international steel structures manufacturer and the analysis serves to verify the structural response of their product, the considered topic may be further extended in many directions, according to the needs of the manufacturer. Thus, the column may be a potential subject of further works. 


\section{References}

1. M. Dabaon, E. Ellobody, K. Ramzy, Nonlinear behaviour of built-up cold-formed steel section battened columns, Journal of Constructional Steel Research, 110 (2015)

2. Y. H. Lee, C. S. Tan, S. Mohammad, In-plane sway behaviour of slender cold-formed steel bolted frames, Thin-walled Structures, 114 (2017)

3. K. Słowiński, W. Wuwer, Investigations of closely spaced build-up bars with flexible joints, The 6th International Conference on Thin Walled Structures (2011)

4. R. Zaharia, D. Dubina, Stiffness of joints in bolted connected cold-formed steel trusses, Journal of Constructional Steel Research, 62 (2006)

5. J. Zhang, B. Young, Numerical investigation and design of cold-formed steel built-up open section columns with longitudinal stiffeners, Thin-walled Structures, 89 (2015)

6. M. Gordziej-Zagórowska, E. Urbańska-Galewska, Ł. Pyrzowski, The validation process of truss model with joint eccentricities, Shell Structures: Theory and Applications, 4 (to be published)

7. P. Deniziak, K. Winkelmann, TS-based RSM-aided design of cold-formed steel stiffened C-sectional columns susceptible to buckling, Shell Structures: Theory and Applications, 4 (to be published)

8. EN 1993-1-6, Eurocode 3 - Design of steel structures - Part 1-6: Strength and Stability of Shell Structures.

9. M. Gordziej-Zagórowska, $\mathrm{PhD}$ thesis, Wpływ mimośrodów na nośność węzłów dźwigarów kratownicowych wykonanych $z$ ksztaltowników giętych na zimno o przekrojach otwartych (2017) [in Polish]

10. G. Watts, M.K. Singha, S. Pradyumna, Nonlinear bending and snap-through instability analyses of conical shell panels using element free Galerkin method, Thin-walled Structures, 122 (2018)

11. P. Mika, Analiza MES zagadnień sprężysto-plastycznych-program Abaqus, 13 (2011) [in Polish]

12. S. Selvaraj, M. Madhavan, Geometric imperfection measurements on cold-formed steel channels, Wiley Online Library (2017) 